\title{
The European Respiratory Society plans its future: the 2013-2018 strategic plan
}

\author{
Giovanni Battista Migliori' ${ }^{1,16}$, Klaus F. Rabe $2,3,4,5,16$, Elisabeth Bel ${ }^{6}$, Mark Elliott7, \\ Mina Gaga ${ }^{8}$, Stephen T. Holgate ${ }^{9}$, Guy Joos ${ }^{10}$, Fernando Martin Burrieza ${ }^{11}$, \\ Betty Sax ${ }^{11}$, Jean-Paul Sculier ${ }^{12}$, Anita K. Simonds ${ }^{13}$, Francesco Blasi ${ }^{14}$ and \\ Peter J. Barnes ${ }^{15}$
}

Affiliations: 'WHO Collaborating Centre for TB and Lung Diseases, Fondazione S. Maugeri, Care and Research Institute, Tradate, and ${ }^{14}$ Dipartimento Fisiopatologia Medico-Chirurgica e dei Trapianti, University of Milan, IRCCS Fondazione Cà Granda, Milan, Italy. ${ }^{2}$ Dept of Internal Medicine, Christian Albrechts University Kiel, Kiel, ${ }^{3}$ Dept of Pulmonary Medicine, LungenClinic Grosshansdorf, Grosshansdorf, ${ }^{4}$ Airway Research Center North (ARCN), Grosshansdorf, and ${ }^{5}$ German Center for Lung Research (DZL), Grosshansdorf, Germany. ${ }^{6}$ Dept of Respiratory Medicine, Academic Medical Center, University of Amsterdam, Amsterdam, The Netherlands.

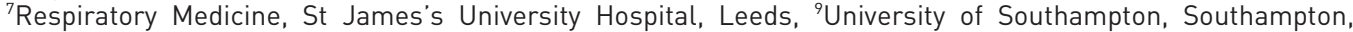
${ }^{13}$ NIHR Respiratory Biomedical Research Unit, Royal Brompton Hospital, London, and ${ }^{15}$ National Heart and Lung Institute, Imperial College, London, UK. ${ }^{87 t h ~ R e s p i r a t o r y ~ M e d i c i n e ~ D e p t, ~ A t h e n s ~ C h e s t ~ H o s p i t a l, ~ A t h e n s, ~}$ Greece. ${ }^{10}$ Dept Respiratory Medicine, Ghent University Hospital, Ghent, and ${ }^{12}$ Depts of Oncological Intensive Care and Emergencies and Thoracic Oncology, Institut Jules Bordet, Université Libre de Bruxelles (ULB), Brussels, Belgium. ${ }^{11}$ European Respiratory Society, Lausanne, Switzerland. ${ }^{16}$ Both authors contributed equally.

Correspondence: G.B. Migliori, WHO Collaborating Centre for TB and Lung Diseases, Fondazione Salvatore Maugeri, Care and Research Institute, via Roncaccio 16, 21049, Tradate (VA), Italy. E-mail: giovannibattista. miglioriafsm.it

○ @ERSpublications

The new ERS 2013-2018 strategy is based on its three pillars: science, education and advocacy http://ow.ly/sSg4V

The European Respiratory Society (ERS), in order to serve better its members and achieve its mission objectives (table 1) [1], organised a Strategy Meeting to plan its core strategic priorities for the period 20132018, taking into account changes occurring both within the society and within the respiratory field in Europe and beyond. This meeting was held on July 3 and 4, 2013 in Lausanne, Switzerland to formulate future directions. We took into account the Executive Summary of the 2006-2007 Strategy Meeting [2] summarising the ERS pillars (fig. 1) and the recently published ERS Presidential plans as an operational guide [3-5].

The Strategy Meeting involved the ERS Leadership represented by the members of the Steering Committee (fig. 2). It was prepared by an ad hoc meeting preceding the event, involving the Past President and the Secretary General Elect (the officers designated to act as chair and moderator), as well as the Executive Director and the Head of the Executive Office. This was used as the starting point to develop the strategic meeting agenda. Participants were encouraged to express their opinions freely and to think "outside the box" in order to bring fresh ideas to the table. Whilst the focus of the exercise was definitely the future,

G.B. Migliori is the ERS Secretary General, K.F. Rabe was the ERS President from 2011 to 2012, E. Bel is the ERS President-Elect, M. Elliott is the ERS Treasurer, M. Gaga was the ERS Secretary General from 2010 to 2013, S.T. Holgate is the Chair of the ERS Scientific Committee, G. Joos was the ERS Treasurer from 2010 to 2013, F. Martin Burrieza is the ERS Executive Director, B. Sax is Head of the ERS Executive Office, J-P. Sculier is the Secretary for European Affairs and Chair of the ERS Advocacy Committee, A.K. Simonds is the Chair of the ERS School, F. Blasi is the ERS Past President, and P.J. Barnes is the ERS President.

Received: Dec 192013 | Accepted: Dec 192013

Conflict of interest: Disclosures can be found alongside the online version of this article at www.erj.ersjournals.com F. Martin Burrieza and B. Sax are employees of the European Respiratory Society. 


\section{TABLE 1 Objectives and means of action of the European Respiratory Society (ERS)}

\section{Objectives}

The objective of the society is to promote respiratory health in order to alleviate suffering from respiratory disease

In the context of these statutes "respiratory medicine" encompasses all aspects of respiratory science and of clinical respiratory practice

These objectives shall be achieved by promoting, co-ordinating, and stimulating the activities of ERS members, facilitating scientific exchange and by advocacy towards governments, granting agencies and political bodies, in co-ordination with national societies, in the fields of education, patient care, public health and research

\section{Powers and means of action}

Promote basic, epidemiological and clinical research in respiratory medicine

Be a reference authority for respiratory medicine in Europe

Collect, assess and disseminate scientific information concerning all aspects of lung health and disease

Organise congresses, conferences, symposia, seminars, scientific meetings, exhibitions and all other clinical and scientific events

Produce scientific publications by the editing, printing, and publishing of reviews, journals, bulletins and any written, visual, audio-visual or electronic media designed to promote, encourage or disseminate research or educational work in the field of respiratory medicine

Support training in respiratory medicine and research through grants and fellowships

Encourage and support continuous education in respiratory medicine

Collaborate with other national and international organisations having a similar objective or similar functions

Engage in appropriate actions to defend its members' interests

Promote collaboration with organisations representing patients with respiratory diseases

Establish branch offices in other cities or countries as required

Derived from Articles I and II of the ERS Constitution [1].

the importance of the past as the basis of all change was emphasised by the presence of the former Executive Director who attended in an observer role to recall the history of the ERS and previous decisions.

Operational minutes discussions were first drafted to allow an accurate summary of the decisions taken, which were then approved by the Steering and Executive Committees following ERS regulations. As it was felt that in the 2006-2007 strategic document a section on implementation, monitoring and evaluation was missing (leading to suboptimal impact of the decisions taken), the present document was developed according to the principles of strategic planning.

The agenda included eight strategic areas for decision: 1) remaining European or "going global"; 2) expanding membership; 3) coordinating with other societies; 4) strengthening science; 5) improving education; 6) improving publications; 7) coordinating and enhancing advocacy; and 8) organisational changes to put in practice the decisions taken.

A specific business plan for implementation of the activities will be developed for each strategic area under the responsibility of the President and the Secretary General together with the Executive Director/ERS office, in alignment with the ERS budget process.

The main decisions taken are summarised in table 2.

\section{Strategic decision 1: remaining European or going global?}

Based on the huge economic challenges that Europe is facing and the changes occurring in regulations with the potential to directly reduce the numbers of people who are able to attend international conferences (the ERS currently remains largely dependent on its International Congress as its main revenue source), opportunities exist for playing a proactive international role.

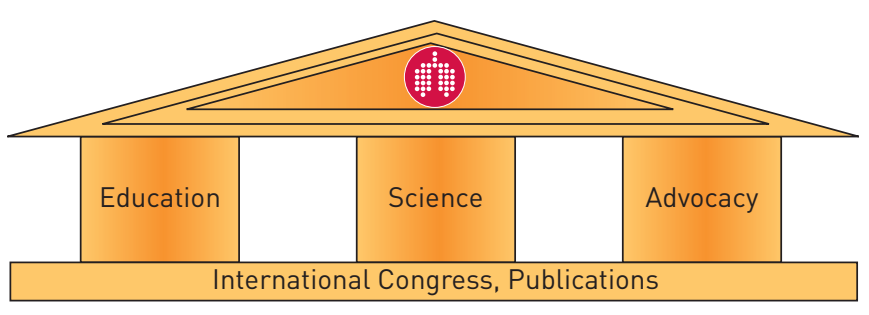

FIGURE 1 The three pillars of the European Respiratory Society. 
FIGURE 2 The European Respiratory Society Strategy Meeting in Lausanne, Switzerland.

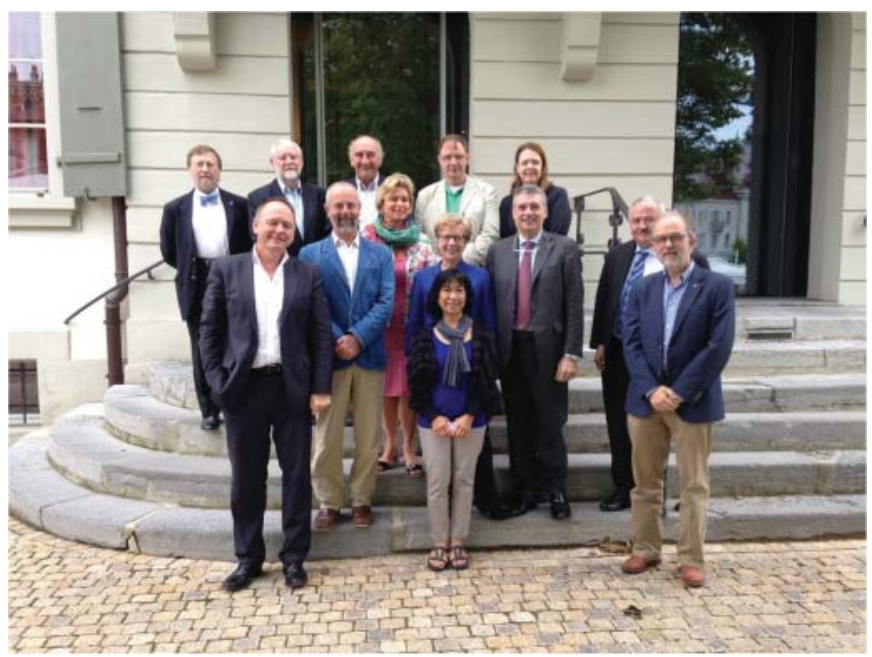

The following decisions were reached.

1) ERS will remain a European society, with European Union (EU)-centred activities, but will be further developed to become attractive and relevant to respiratory communities outside Europe. This "magnet" effect will encourage global participation in the ERS International Congress because of its excellence and high-level networking opportunities.

2) ERS will share expertise with regional/national respiratory societies through joint activities, which will empower them to bring the acquired knowledge to their respective constituents.

3) ERS will maintain excellence in its scientific and clinical programme at the Congress, as well as in basic and translational research and education activities.

4) International involvement will be increased at the Congress at all levels (speakers, chairs and participation in Assembly meetings). To this effect, the creation of an International Programme Committee will be implemented.

\section{Strategic decision 2: expanding membership}

Taking into account the large number of nonmember Congress participants compared with attendees who are ERS members and the short-term membership measures presented by the Secretary General and approved by the Executive Committee at the meeting in Zurich, Switzerland, in 2013, it was agreed the following.

1) To underscore/highlight the basis of the ERS membership campaign: the revenue generated does not at all represent the true value of ERS membership. The contacts and the possible interactions initiated by each member bring the real benefit of the society.

2) To increase the individual membership via the ERS magnet effect (especially in Eastern Europe, Asia and Latin America) by offering a single affordable fee for the whole membership in collaboration with national societies in Europe and regional societies outside.

3) To work on an analysis of the membership database with the membership marketing team in the ERS office and come up with a communication plan.

4) To work towards the establishment of a Fellowship of the ERS (FERS) to recognise outstanding contributions to respiratory research, education and clinical practice.

\section{Strategic decision 3: coordinating with other societies}

Emphasising the importance of unified action to promote global respiratory health, the following agreements were reached.

1) The ERS will strengthen links with other major national and international respiratory societies through regular meetings, and consider joint programmes where appropriate.

2) The ERS will participate as an active member of the Forum of International Respiratory Societies to promote global respiratory health.

In addition, the ERS will work with other specialist organisations where appropriate, including the following. 


\section{TABLE 2 Summary of the main future directions of the European Respiratory Society (ERS)}

1) ERS will maintain its European character but will adhere to activities that will result in its evolution as a global "magnet" leading to international membership and participation in its activities

2) ERS will adopt a simple and affordable membership fee scheme to foster increased membership numbers

3) ERS will launch the Fellowship of the ERS (FERS) programme

4) ERS will support the establishment of a strong world federation of respiratory societies involved in global respiratory health

5) ERS, through its Scientific Council, will restructure its Assemblies

6) ERS Scientific and Educational Activities ("School") Councils will develop a joint plan

7) ERS will explore the development of a research agency

8) ERS will re-organise its advocacy strategy centred around the Advocacy Committee and ELF for Patients

9) ERS will tune its corporate business model and will undertake the necessary rationalisation of offices and staff

10) ERS will establish a corporate marketing plan

11) ERS will adjust its governance/information technology/finance and communications operational functions to enable implementation of strategy committee decisions

ELF: European Lung Foundation.

\section{Biomedical Alliance of Research in Europe}

The ERS is one of the four founding members of the Biomedical Alliance, which now includes over 20 specialist societies, representing over 400000 specialists. The Biomedical Alliance has an important voice in promoting the importance of clinical and translational research, and in influencing decision makers in the EU on finding choices [6].

\section{World Health Organization}

The ERS will work with the World Health Organization in organising joint meetings, workshops and advocacy for respiratory health in tuberculosis and noncommunicable diseases.

\section{Strategic decision 4: strengthening science}

The outcomes of the scientific strategy meeting (April 2013) emphasising the role of science (basic, translational and clinical research) as a major pillar of the ERS guided the discussion.

It was agreed to take the following action.

1) Embed the Scientific Strategy within the ERS strategy, as science should thread through all the society's activities.

2) Advance in restructuring the Assemblies, with a view to having basic science, clinical medicine and education as cross-cutting themes and disease-related assemblies (fig. 3).

3) Develop a plan to launch an ERS Research Agency, which will coordinate and fund respiratory research across Europe, for example building databases, research registries and biobanks. This will involve the recruitment of new staff with a scientific background. It will also involve establishing a partnership with the research and development departments of pharmaceutical and diagnostics companies.

\section{Strategic decision 5: improving education}

Considering that education is a pillar of the ERS, including Harmonised Education in Respiratory Medicine for European Specialists (HERMES), e-learning, assessments and educational publications [7-13], the following agreements were reached.

1) Ensure full support to achieve the most comprehensive respiratory education in the world.

2) Promote better integration between the Scientific and Education Activities departments, including joint management of fellowships and grants.

3) Ensure that the School strategy is embedded into an Education Strategy.

4) Develop a business plan emanating from the questions submitted by the School Committee.

5) Balance continuing professional education, continuing medical education and accreditation within School activities.

6) Attract better links to allied health professionals and primary care.

7) Seek agreements for HERMES worldwide, as well as revalidation programmes.

8) Incorporate professional education staff (i.e. revisit the concept of a separate education department in the ERS office).

9) Consider re-naming the committee/department "Education" rather than "School". 


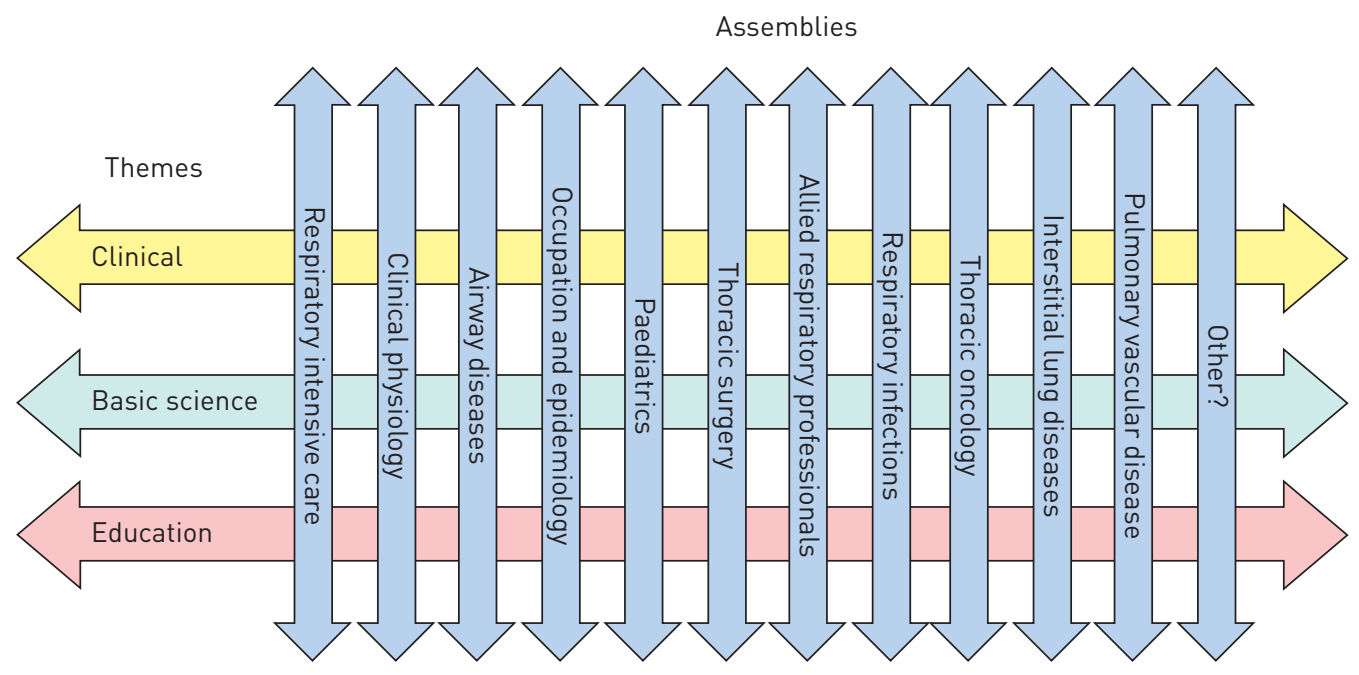

FIGURE 3 A potential operative matrix for the structure of the European Respiratory Society, showing how educational, clinical and basic research activities cut across the disease-specific Assemblies. Reproduced from [3].

\section{Strategic decision 6: improving publications}

Publications are a crosscutting segment of ERS activities, moving across science, education, advocacy and international links [14-19]. Based on the 5-year strategy presented by the Publications Committee in 2011, several core topics were discussed including further professionalising European Respiratory Journal editors and its Editorial Board, a possible future extension of the Chief Editor's mandate, and rationalisation of the location of publications.

The Publication Strategy will be revised by the Steering Committee with the support of the Secretary General and the Executive Director/ERS office, in coordination with the Chair of the Publication Committee, and, consequently, presented to the Executive Committee in connection with the strategies related to the other pillars.

\section{Strategic decision 7: coordinating and enhancing advocacy}

The current overall structure requires revision and restructuring to avoid overlap in functions of the European Lung Foundation (ELF) and the ERS, with ELF being clearly identified as a unit within the ERS rather than a separate organisation operating independently (with its fundraising efforts sometimes conflicting with ERS corporate relations). The overlap in advocacy activities of ERS/ELF can be resolved by establishing "ELF for Patients" to handle patient-related advocacy and the Brussels office being given the remit for researchrelated advocacy. A coordination plan will be implemented to rationalise and streamline these partnerships/ links for greater efficiency and impact, with clear assignment of ERS representation in every activity.

The following agreements were reached.

1) The structure of ELF needs revision.

2) It is necessary to differentiate between patients and advocacy, and fundraising.

3) The new name for ELF will be "ELF for Patients".

4) The Brussels Office will have the remit for ERS advocacy.

5) A rationalisation plan of ELF for patients and ERS advocacy will be developed.

\section{Strategic decision 8: implementing strategic decisions via organisational changes ERS business model}

A final plan, based on the draft rationale for a marketing plan for ERS corporate strategy discussed during the Strategy Meeting (aimed at better defining future corporate relations and executive direction) will be finalised by the end of 2013 .

\section{ERS human resources}

A careful look at the development of staff and resources will be based on separating education and science from research activities. The core person for the Research Agency (initially as a consultant) will be identified, as well as a core specialist for Education. The possibility of creating an ERS business school was brought to the table for open discussion. Defining an ERS career path to attract junior members to a 
long-standing commitment of service to the ERS was considered. To achieve this, it will be advisable to offer courses via the School to coach professional society officers and develop procedures for personal and teamwork assessment.

\section{ERS staff}

A new core staff person for research is needed, with potential partners for outsourcing services being identified. A plan for internal career development of managers should be put in place, as currently there is very limited potential for staff advancement, offering few incentives for staff to make service to the ERS their long-term career. The ERS should develop a policy of, and assessment of, the job description and performance of the Executive Director every 4-8 years, with a potential trainee/deputy Executive Director candidate to be identified internally early in the process to allow for a long-term replacement plan. Greater involvement of the officer in charge of the office (Secretary General) should be also encouraged, and procedures for personal and teamwork assessment established and implemented.

\section{ERS information technology}

To act effectively and to implement plans, the ERS needs a reliable database and adequate data management tools upon which to build strategies. As this will require reinforcement of information technology (IT) capacity of the ERS office, a business plan for IT will be developed with operations that will be adapted to, and in coordination with, the direction set by discussions of the Strategy Meeting.

External consultancy may need to be called upon for state-of-the-art revision of current systems and proceedings.

\section{ERS communication strategy}

It was considered imperative that all ERS activities present a unified corporate identity and communications strategy, to be reflected in internal and external procedures within a communications plan that will coordinate the needs of all ERS instances.

\section{Conclusions}

A stronger ERS will ensure stronger advocacy to support respiratory health both at the EU and global levels. We are confident that a joint effort involving the ERS leadership, members and staff will ensure a successful design and implementation of the different plans composing the 2013-2018 ERS strategy, having our patients in mind as the ultimate beneficiaries and the advancement of respiratory science as the way to better serve them.

\section{References}

1 The European Respiratory Society. Constitution. www.ersnet.org/images/stories/pdf/Constitution_ADOPTED_ in_Vienna_2012.pdf Date last updated: September 2012.

McNee W. The ERS Strategy Report, Lausanne, European Respiratory Society, 2007.

Blasi F, Barnes PJ, Gaga M, et al. Future directions for the ERS: Presidential plans. Eur Respir J 2013; 42: 875-880. Blasi F, Reichman LB, Migliori GB. Presenting the European Forum for TB Innovation: innovative thinking in progressing towards TB elimination in Europe. Eur Respir J 2012; 40: 806-808.

Blasi F, Dara M, van derWerf MJ, et al. Supporting TB clinicians managing difficult cases: the ERS/WHO Consilium. Eur Respir J 2013; 41: 491-494.

6 Nicod LP, Kamel N, Ward B, et al. ERS is founding member of a new Alliance for Biomedical Research in Europe. Eur Respir J 2011; 38: 237-238.

7 Loddenkemper R, Séverin T, Mitchell S, et al. HERMES criteria for accreditation of European Training Centres: overcoming challenges of accreditation. Eur Respir J 2010; 36: 1239-1241.

8 De Backer W, Simonds AK, Horn V, et al. Sleep HERMES: a European training project for respiratory sleep medicine. Eur Respir J 2011; 38: 496-497.

9 Artigas A, Pelosi P, Dellweg D, et al. Respiratory critical care HERMES syllabus: defining competencies for respiratory doctors. Eur Respir J 2012; 39: 1294-1297.

10 Gamarra F, Boffetta P, De Ruysscher D, et al. Thoracic Oncology HERMES syllabus: setting the basis for thoracic oncology training in Europe. Eur Respir J 2013; 42: 568-571.

11 Steenbruggen I, Mitchell S, Séverin T, et al. Harmonising spirometry education with HERMES: training a new generation of qualified spirometry practitioners across Europe. Eur Respir J 2011; 37: 479-481.

12 Gappa M, Paton J, Baraldi E, et al. Paediatric HERMES: update of the European Training Syllabus for Paediatric Respiratory Medicine. Eur Respir J 2009; 33: 464-465.

13 Loddenkemper R, Séverin T, Haslam PL. European curriculum recommendations for training in adult respiratory medicine: crossing boundaries with HERMES. Eur Respir J 2008; 32: 538-540.

14 Migliori GB, Soriano JB, Brusasco V, et al. ERJ peer reviewers: does this pillar of the Journal's quality need help? Eur Respir J 2011; 38: 251-252.

Dinh-Xuan AT, Brusasco V. The making of the ERJ: behind the scenes and Editors' cut. Eur Respir J 2010; 36: 4-5. Dinh-Xuan AT, Brusasco V, Wedzicha JA, et al. ERS publications: the flagship and the fleet. Eur Respir J2012; 40: 535-537. Dinh-Xuan AT, Brusasco V. The editors' farewell and a confident look back to the future. Eur Respir J2012; 40: 1309-1311. Humbert M. The ambition of the European Respiratory Journal. Eur Respir J 2013; 41: 1-2.

Humbert M, Simonneau G, Dinh-Xuan AT. Whistleblowers. Eur Respir J 2011; 38: 510-511. 